\title{
Fluoridated Water Supply and Promotion of Oral Health in Children of Low Socioeconomic Status- A Cross-Section Study Cruvinel $\mathrm{VR}^{* 1}$, Gravina $\mathrm{DB}^{2}$, Peruchi $\mathrm{CM}^{1}$, Bezerra $\mathrm{AC}^{3}$ and Toledo $\mathrm{OA}^{1}$
}

${ }^{1}$ Depratment of Pediatric Dentistry, School of Dentistry, Catholic University of Brasília, Brasília, (DF), Brazil

${ }^{2}$ Depratment of Pediatric Dentistry, University of Brasília, Brasília, Brazil

${ }^{3}$ Depratment of Public Health, Faculty of Ceilândia, University of Brasília, Brasília, Brazil

${ }^{*}$ Corresponding author: Cruvinel VR, Depratment of Pediatric Dentistry, School of Dentistry, Catholic University of Brasília, Brasília, (DF), Brazil, Email: vanessarcruvinel@gmail.com

Citation: Cruvinel VR, Gravina DB, Peruchi CM, Bezerra AC, Toledo OA (2015) Fluoridated Water Supply and Promotion of Oral Health in Children of Low Socioeconomic Status- A Cross-Section Study. J Dent Oral Care Med 1(2): 201. doi: 10.15744/2454-3276.1.201

Received Date: May 05, 2015 Accepted Date: August 04, 2015 Published Date: August 05, 2015

\begin{abstract}
The purpose of this study was to conduct epidemiological research of the oral health conditions and needs of public school children who live and study in fluoridated and non-fluoridated areas of Brasilia, Brazil. The sample was selected based on the evaluation of the clinical cards of 562 children, from ages 6 to 17. For this research the children were classified based on their treatment needs according to priorities 01 , 02 and 03 . The clinical cards were divided into two groups according to the addresses of the schools. Group 1 (G1) corresponds to schools with non-fluoridated water. Group 2 (G2) corresponds to schools with fluoridated water. The results in G1, 62.7\% (n=103) of the children presented Priority 1 treatment need, 27.5\% ( $\mathrm{n}=45)$ Priority 2 and just 9.8\% ( $\mathrm{n}=17$ ) Priority 3. In G2, 36.2\% ( $\mathrm{n}=143)$ present Priority $1,25.7 \%$ $(\mathrm{n}=102)$ present Priority 2 and $38.1 \%(\mathrm{n}=152)$ present Priority 3 . There was a statistically significant difference between the two groups ( $\mathrm{p}$ 0.001). When the children were divided into age groups $(6-9 ; 10-13 ; 14-17)$, the younger children of G1 showed an average of 3.76 teeth needing treatment; in G2, the average was about 1.67 teeth per child showing ( $\mathrm{p} 0.001$ ). The results demonstrated that the children who did not use fluoridated water (G1) had worse oral health conditions. In the 6-9 year age group, a significant difference in the treatment needs (restoration and exodontics) was found between G1 and G2. In the 10-13 year age group, the only significant need found was for restoration between G1 and G2. This shows the necessity of improving the fluoridated water supply in Brazil, especially for young children in low socioeconomic conditions.

Keywords: Dental caries; Children; Fluorides; Socioeconomic factors
\end{abstract}

\section{Introduction}

Epidemiological studies now show that diseases in general are related directly to social conditions and not only to biological factors that, in the past, were considered the main determinants. Cultural differences, low education, low family income and cultural habits are risk factors related directly to the development of oral diseases such as caries and periodontal disease [1-4].

Socio-economic factors and oral hygiene behaviors have a direct influence on the health conditions of the child population [5], where higher rates of decay were found in the population with lower income and lower educational level. According to the survey by the Ministry of Health, caries is a "social" disease that can be reduced or even avoided through comprehensive public policies involving promotion and health education, offering curative actions where necessary, within a conservative philosophy that is focused on prevention [6,7].

In addition to the inequalities of access to dental services, people with pronounced differences in income are also at a disadvantage regarding the population coverage of preventive methods as strategies to promote oral health. Fluoridation of water supplies can still be considered as the main, large-scale preventive method in developing countries, responsible for the high decline in the prevalence of caries among the population [8].

The strategy of fluoridation of public water supplies reduces oral health inequities [9]. The poorest people are the most vulnerable to dental caries when fluoridation either is not done or is discontinued. The Brazilian experience shows that, in practice, the benefit is proportionally larger in segments that do not have access to other protective factors: that such access is markedly restricted. Therefore, those most in need not only get the benefit but, for them, this protective factor is stronger [10]. Thus, fluoridation of the public water supply has enormous "universal" potential and, moreover, helps people to have access to drinking water, perhaps the most important public health action [11]. Therefore, it can be considered "socially unjust" not to perform it or to stop it [12].

There are still many regions in Brazil with non-fluoridated water supply, especially rural areas. In both cases, access to oral prevention and treatment are difficult, so the use of such a strategy would be fair and would avoid illness [12]. Children who live in these areas have greater risk, in relation to others of the same socioeconomic status who live in fluoridated regions, for developing dental caries. 
It is true that, for some people with high susceptibility to oral diseases, a population strategy based on non-individualized measures is not enough. Such cases call for a high-risk strategy to complement them. Although, individualized attention is expensive, the positive effects are usually temporary, and it is not able to prevent the recurrence of disease [13]. The combination of the two strategies - population and high-risk - is essential for achieving and maintaining oral health; however, the balance of effort clearly should be focused on the first $[13,14]$.

In 2002 in Brasília, Brazil established a Politic strategy for poor people; it was named "My Income Program". This strategy aims to support the educational and health areas, including dental, ophthalmic and nutritional assistance, with quality and resolute actions for low-income students in the Public Network selected to receive benefits. This program also comprises preventive dentistry activities associated with healing practices (high-risk strategy), in order to promote the protection and recovery of the students' oral health. Lectures, educational films, supervised brushing, topical fluoride application and surveys of dental needs are some of the preventive actions developed.

Considering that oral health is important for the complete well-being of the individual and essential to the learning process of the child / adolescent, this study aimed to compare the oral health conditions of children living and studying in areas of fluoridated water supply with those of children living and studying in areas without fluoridated water supply. Both areas are located in Brasilia, Brazil.

\section{Material and Method}

Prior to this study, in 2006, five (5) dentists of the Oral Health teams from Brasilia (Brazil) visited 46 public schools, 39 from areas with fluoridated water and 7 from areas with non-fluoridated water, to survey the dental needs of 5087 students belonging to the "My Income Program". Of these, 4397 students were living in the fluoridated area and 690 students were living in the nonfluoridated area.

This study is analytical, observational, quantitative and documental, with analysis of the medical records of 562 children between 6 and 17 years of age and low socioeconomic status. The children were divided into 3 age groups: 6 to 9 years, 10 to 13 years and 14 to 17 years.

The records to be analyzed were chosen using a systematic random sampling process with a sampling error of 5\%, a confidence interval of 95\% and divided into 2 groups: Group 1 (G1), corresponding to children living in areas without fluoridated water supply; and Group 2 (G2), corresponding to children living in areas with fluoridated water. There were 165 students in G1: 51 of them aged 6 to 9,80 of them aged 10 to 13 , and 34 of them aged 10 to 14 . The remaining 397 students were in G2: 105 of them aged 6 to 9,206 of them aged 10 to 13 , and 86 of them aged 14 to 17 .

From the analysis of the records, the students were placed in a specific group. This classification was based on age, sex, priority needs for treatment, and preventive and curative procedures performed for the promotion of oral health.

The needs assessment was conducted based on the priority ranking, according to the following criteria:

- Priority 01: extractions, changes of any abnormality in the oral cavity needing urgent care, or more than four carious lesions;

- Priority 02: presence of up to four carious lesions;

- Priority 03: absence of carious lesions or other pathologies.

For statistical analysis, the Fisher's exact test was used to analyze sex, extraction, and need for endodontics; the Student's t-test was used for assessment of age; and, the Pearson chi-square test was used to analyze the priorities. A significance level of $\mathrm{p}<0.05$ was established.

\section{Results}

A total of 283 girls and 279 boys, distributed between G1 and G2, were included. There was no statistically significant difference in the distribution of sex between the groups, $\mathrm{p}=0.089$ (Table 1 ).

\begin{tabular}{|c|c|c|c|c|c|}
\hline \multirow[t]{2}{*}{ Variables } & \multicolumn{2}{|c|}{ G1- Non-fluoridated water supply } & \multicolumn{2}{|c|}{ G2 - With fluoridated water supply } & \multirow[t]{2}{*}{$\mathbf{P}$} \\
\hline & Total Population & Sample & Total Population & Sample & \\
\hline \multicolumn{5}{|c|}{ Age range/years } & \multirow[t]{4}{*}{0.636} \\
\hline 6 to 9 & 229 & 51 & 1492 & 105 & \\
\hline 10 to 13 & 346 & 80 & 1980 & 206 & \\
\hline 14 to 17 & 115 & 34 & 925 & 86 & \\
\hline \multicolumn{5}{|l|}{ Sex } & \multirow[t]{3}{*}{0.089} \\
\hline Male & 316 & 74 & 2245 & 205 & \\
\hline Female & 374 & 91 & 2152 & 193 & \\
\hline
\end{tabular}

Table 1: Number of students per age range in groups G1 and G2 
Based on the evaluation of the ages, it was observed that the average age in groups G1 and G2 was around 11 years, $p=0.636$, with no statistically significant difference between the groups.

Regarding students needing treatment in the age groups 6-9, 10-13 and 14 to 17 years in the 2 groups, the p values were 0.001 , 0.036 and 0.153 , respectively. This shows a significant difference in children aged 6-9 years and 10-13 (Table 2).

\begin{tabular}{|c|c|c|c|c|c|}
\hline \multirow[t]{3}{*}{ Priorities } & \multicolumn{4}{|c|}{ Population studied: 562} & \multirow[t]{3}{*}{ p-value } \\
\hline & \multicolumn{2}{|c|}{ Group I } & \multicolumn{2}{|c|}{ Group II } & \\
\hline & $\mathbf{N}$ & $\%$ & $\mathbf{N}$ & $\%$ & \\
\hline \multicolumn{5}{|c|}{ Groups aged 6 to 9} & \multirow[t]{5}{*}{0.001} \\
\hline$\bullet 1$ & 32 & 62.7 & 38 & 36.2 & \\
\hline - 2 & 14 & 27.5 & 27 & 25.7 & \\
\hline - 3 & 5 & 9.8 & 40 & 38.1 & \\
\hline Total & 51 & 100 & 105 & 100 & \\
\hline \multicolumn{5}{|c|}{ Groups aged 10 to 13} & \multirow[t]{5}{*}{0.036} \\
\hline$\bullet 1$ & 20 & 25.0 & 39 & 18.9 & \\
\hline$\cdot 2$ & 35 & 43.8 & 68 & 33.0 & \\
\hline - 3 & 25 & 31.2 & 99 & 48.1 & \\
\hline Total & 80 & 100 & 206 & 100 & \\
\hline \multicolumn{5}{|c|}{ Groups aged 14 to 17} & \multirow[t]{5}{*}{0.153} \\
\hline$\bullet 1$ & 7 & 20.6 & 11 & 11 & \\
\hline - 2 & 15 & 44.1 & 28 & 28 & \\
\hline$\cdot 3$ & 12 & 35.3 & 47 & 47 & \\
\hline Total & 34 & 100 & 86 & 86 & \\
\hline
\end{tabular}

From the assessment of priorities, the number of teeth of each child who needed treatment, including restoration procedures, extractions and endodontic indication for root canal, was verified. There was an average of 3.76 teeth per child in the 6-9 years age group in G1, and 1.67 teeth per child in G2. The value of $\mathrm{p}$ was $<0.001$, showing a highly significant difference. In other age groups, the p values were 0.007 and 0.634 , respectively, showing no significant differences (Table 3 ).

\begin{tabular}{|c|c|c|c|c|c|c|}
\hline Age & Group & Mean & $\begin{array}{l}\text { Standard } \\
\text { Deviation }\end{array}$ & $\mathbf{P}$ & $\mathbf{T}$ & $\begin{array}{l}\text { Mean } \\
\text { Difference }\end{array}$ \\
\hline \multirow[t]{2}{*}{6 to 9} & G1 & 3.76 & 3.344 & \multirow[t]{2}{*}{$<0.001$} & \multirow[t]{2}{*}{4.799} & \multirow[t]{2}{*}{2.098} \\
\hline & G2 & 1.67 & 2.083 & & & \\
\hline \multirow[t]{2}{*}{10 to 13} & G1 & 1.45 & 1.413 & \multirow[t]{2}{*}{0.007} & \multirow[t]{2}{*}{2.731} & \multirow[t]{2}{*}{0.479} \\
\hline & G2 & 0.97 & 1.299 & & & \\
\hline \multirow[t]{2}{*}{14 to 17} & G1 & 1.09 & 1.288 & \multirow[t]{2}{*}{0.634} & \multirow[t]{2}{*}{0.478} & \multirow[t]{2}{*}{0.158} \\
\hline & G2 & 0.93 & 1.748 & & & \\
\hline
\end{tabular}

Table 3: Number of teeth needing treatment in the 3 age ranges

Table 4 shows the average number of teeth in need of restoration, extraction and endodontics in different age groups, with statistical significance only in the 6-9 year age group in relation to restorations and extractions to be performed ( $\mathrm{p}<0.01$ and $\mathrm{p}=$ 0.01 , respectively). In the 10-13 year age group, there was statistically significant difference between groups regarding the need for restoration $(\mathrm{p}=0.009)$. In the $14-17$ years age group, there were no statistically significant differences between the groups.

\begin{tabular}{|c|c|c|c|c|c|c|}
\hline Group & \multicolumn{2}{|l|}{ Age } & \multicolumn{2}{|l|}{ Age } & \multicolumn{2}{|l|}{ Age } \\
\hline & \multicolumn{2}{|c|}{$6-9$ years } & \multicolumn{2}{|c|}{$10-13$ years } & \multicolumn{2}{|c|}{$14-17$ years } \\
\hline & Mean & $\mathrm{SD}$ & Mean & $\mathrm{SD}$ & Mean & SD \\
\hline \multicolumn{7}{|c|}{ Restoration } \\
\hline G1 & 2.65 & 2.862 & 1.04 & 1.119 & 0.76 & 0.987 \\
\hline G2 & 1.16 & 1.777 & 0.66 & 1.073 & 0.77 & 1.713 \\
\hline $\mathrm{P}$ & \multicolumn{2}{|c|}{$<0.001^{*}$} & \multicolumn{2}{|l|}{$0.009^{*}$} & \multicolumn{2}{|l|}{0.993} \\
\hline
\end{tabular}




\begin{tabular}{|l|l|l|l|l|l|l|}
\hline Group & \multicolumn{2}{l|l}{ Age } & \multicolumn{2}{l|}{ Age } & \multicolumn{2}{l|}{ Age } \\
\hline & $6-9$ years & \multicolumn{1}{l|}{$10-13$ years } & \multicolumn{2}{l|}{$14-17$ years } \\
\hline & Mean & SD & Mean & SD & Mean & SD \\
\hline \multicolumn{7}{|l|}{ Exodontics } \\
\hline G1 & 1.08 & 1.495 & 0.34 & 0.728 & 0.12 & 0.409 \\
\hline G2 & 0.44 & 0.950 & 0.29 & 0.733 & 0.06 & 0.320 \\
\hline P & $<0.001^{*}$ & 0.596 & 0.399 \\
\hline Endodontics \\
\hline G1 & 0.04 & 0.196 & 0.08 & 0.309 & 0.21 & 0.410 \\
\hline G2 & 0.07 & 0.318 & 0.02 & 0.154 & 0.10 & 0.344 \\
\hline P & 0.573 & & 0.067 & 0.172 & \\
\hline
\end{tabular}

Table 4: Treatment needs (restoration, exodontics, endodontics) in the 3 age ranges

\section{Discussion}

This study showed the importance of fluoridation of the water supply as a populational strategy. It is the guiding principle of the national oral health policy in Brazil. It is a strategy aimed at the whole population, which should be maintained and prioritized. It is observed that the population served by this resource presents better oral health conditions. Our results, as well as those of other studies [15-17], confirm this relationship.

In Brazil, children who study in public schools have low socioeconomic status. The sample of this study had this status; and, this factor can also contribute to the high prevalence of oral problems found.

Children who lived in areas with no water fluoridation (G1) had worse oral health conditions, as compared to children from areas with water fluoridation (G2). This probably can also be explained by the fact that this strategy reduces dental caries, especially for people with low socioeconomic status. Many of these children didn't have access to oral health promotion and treatment before they were covered by this program, especially the children from G1.

These findings support Barbato, et al. [18] (2015), who report that contextual factors related to where individuals live may also influence tooth loss, since local conditions expose these individuals to environments more or less favorable to oral health.

Another aspect considered in this study is related to water fluoridation. This provided better oral health for the group (G2) living in areas with fluoridated water, even though this group had as low socioeconomic status as the other group (G1) that lived in areas without fluoridated water. This finding also supports Barbato, et al. [18], who consider water fluoridation as a measure to prevent tooth loss. According to these authors, this strategy can contribute to reducing inequalities in oral health.

A great need for procedures such as root canals, extractions and restorative treatments was observed in this study, which corroborates other research [16].

The DMFT was not calculated in this study because past histories of caries, restorations and tooth loss were not included in the records. Therefore, we chose to assess the need for treatment, since that suggests the current situation of the oral health status of the sample. It was clear that the oral health situation was always unfavorable in younger children, in relation to older children. This can be explained by the fact that the permanent teeth of the younger children were present more recently in the oral cavity, plus the appropriate motor coordination, responsibility and care that are already part of the lives of these students. The promotion of individual and populational health measures should be intensified, especially at the collective level. Students living in areas not benefiting from fluoridated water, still having a lower socioeconomic standard. In other research [19], children living in areas with a lower socioeconomic standard showed a poorer awareness of the importance of oral health as compared with those living in areas with a higher socioeconomic standard.

This study supports Barbato, et al. [20], who report that differential access to good services, resources and social facilities, and also social interaction, place of residence and socio-economic structure, are important factors for risks and benefits that influence population health status. Thus, it is considered that the context in which people live provides the synthesis of different combinations of social, economic, structural, demographic and geographic factors, affecting their lives and health.

In the My Income Program, as well as in another study [20], annual return visits occurred with the following measures: clinical examinations, guided brushing sessions, instruction in oral hygiene and diet, fluorotherapy and work on the motivation of children, as well as rehabilitative treatment when necessary. However, $0.4 \%$ of the children had lost permanent teeth and only $41 \%$ were free of caries. Preventive and educational measures need to be reinforced constantly. The annual frequency of return and delivery of services of the program are similar to those in the study of Martins, et al. [20]. 
Regarding the surgical procedures, there was a higher incidence of extractions of deciduous teeth than of permanent teeth. This reinforces the greater need for adopting educational measures and health promotion for younger age groups. Evaluation of the average of endodontic treatments according to the groups studied verified that the $\mathrm{p}$ value was significant (0.036). Analysis of the socioeconomic aspect showed the effectiveness of the oral health program for children and families from the $\mathrm{C}$ and $\mathrm{D}$ socioeconomic classes. In agreement with Freire, 2013 there are significant geographical and socioeconomic inequalities in levels of the disease.

The expansion of these strategies for other groups takes on paramount importance. Coverage, through fluoridation of the water supply, should become a priority of the current health policy. This includes areas with low socioeconomic status, where an alternative measure such as fluoridation of school water, for example, can be applied. Targeted and high-risk strategies should also benefit children in the preschool, 0-5 years of age, and adult and senior groups, who currently constitute the largest oral health problem in this country.

This study was conducted using a sample with low socioeconomic status, so it may have suffered interference from other confounding factors such as educational level, access to basic sanitation and health services that could interfere with the results of treatment, since regions without fluoride have the worst social indicators.

New, longitudinal studies should be conducted to compare these data and to follow these children, to verify the effectiveness of the program over time.

\section{Conclusion}

Children in the age range from 6 to 9 years, especially those who did not live in an area with fluoridated water, had worse oral health in relation to the other age groups. This reinforces the importance of this population-wide strategy for improving the oral health of Brazilian children.

\section{References}

1. Hoffman AM, Branson BG, Keselyak NT, Simmer-Beck M (2014) Preventive services program: a model engaging volunteers to expand community-based oral health services for children. J Dent Hyg 88: 69-77.

2. O’Brien M (1994) Children's Dental Health in the United Kingdom 1993. London: OPCS, Social Survey Division, HMSO.

3. Petersen PE (2004) Inequalities in oral health: the social context for oral health. Chapter 3: Community Oral Health, Quintessence.

4. Petersen PE (1990) Social inequalities in dental health - Towards a theoretical explanation. Community Dent Oral Epidemiol 18: 153-8.

5. Rothen M, Cunha-Cruz J, Zhou L, Mancl L, Jones JS, et al. (2014) Oral hygiene behaviors and caries experience in Northwest PRECEDENT patients. Community Dent Oral Epidemiol 42: 526-35.

6. Ramires I, Buzalaf MA (2007) Fifty years of fluoridation of public water supplies in Brazil benefits for the control of dental caries. Cien Saude Colet 12: 1057-65.

7. Kidd E, Fejerskov O (2013) Caries control in health service practice. Prim Dent J 2: 4.

8. Tenuta LM, Cury JA (2010) Fluoride: its role in dentistry. Braz Oral Res 1: 9-17.

9. Riley JC, Lennon MA, Ellwood RP (1999) The effect of water fluoridation and social inequalities on dental caries in 5-year-old children. Int J Epidemiol 28: 300-5.

10. Al Agili DE, Alaki SM (2014) Can Socioeconomic Status Indicators Predict Caries Risk in Schoolchildren in Saudi Arabia? A Cross-sectional Study. Oral Health Prev Dent 12: 277-88.

11. Carmo CD, Alves CM, Cavalcante PR, Ribeiro CC (2010) Evaluation of fluoride levels in the public water supply in São Luis Island, Maranhão State, Brazil. Cien saude Colet 1: 1835-40.

12. Kalamantiano PA, Narvai PC (2006) Ethical aspects of the use of fluoride products in Brazil: a view of public health policy formulators. Ciência \& Saúde Coletiva 1: 63-9.

13. Freire Mdo C, Reis SC, Figueiredo N, Peres KG, Moreira Rda S, et al. (2013) Individual and contextual determinants of dental caries in Brazilian 12-year-olds in 2010. Rev Saude Publica 3: 40-9.

14. Sheiham A, Joffe M (1991) Public Dental health strategies for identifying and controlling dental caries in high and low risk populations. Risk markers for oral diseases 1: 445-81.

15. Meirelles MPMR, Sousa ML, Wada RS, Hoffman RHS, Cypriano S, et al. (2003) Importance of fluoridation of public water supply in small towns of São Paulo. Anais Brazilian Oral Res 17: 26.

16. McGrady MG, Ellwood RP, Maguire A, Goodwin M, Boothman N, et al. (2012) The association between social deprivation and the prevalence and severity of dental caries and fluorosis in populations with and without water fluoridation. BMC Public Health 12: 1122.

17. Tagliaferro EP, Cypriano S, de Sousa Mda L, Wada RS (2004) Caries experience among schoolchildren in relation to community fluoridation status and town size. Acta Odontol Scand 62: 124-8.

18. Barbato PR, Peres MA, Höfelmann DA, Peres KG (2015) Indicadores contextuais e individuais associados à presença de dentes adultos. Rev Saúde Pública 49: 27.

19. Sampaio FC, Hossain AN, Von der Fehr FR, Arneberg P (2000) Dental caries and sugar intake of children from rural areas with different water fluorides levels in Paraíba, Brazil. Community Dent Oral Epidemiol 28: 307-13.

20. Martins CC, Torres CS, Martins LHPM, Auad SM, Paiva SM, et al. (2002) Impact of preventive maintenance on Dental Caries Experience in Children 12 years old. Revista JBP 26: 302-8. 


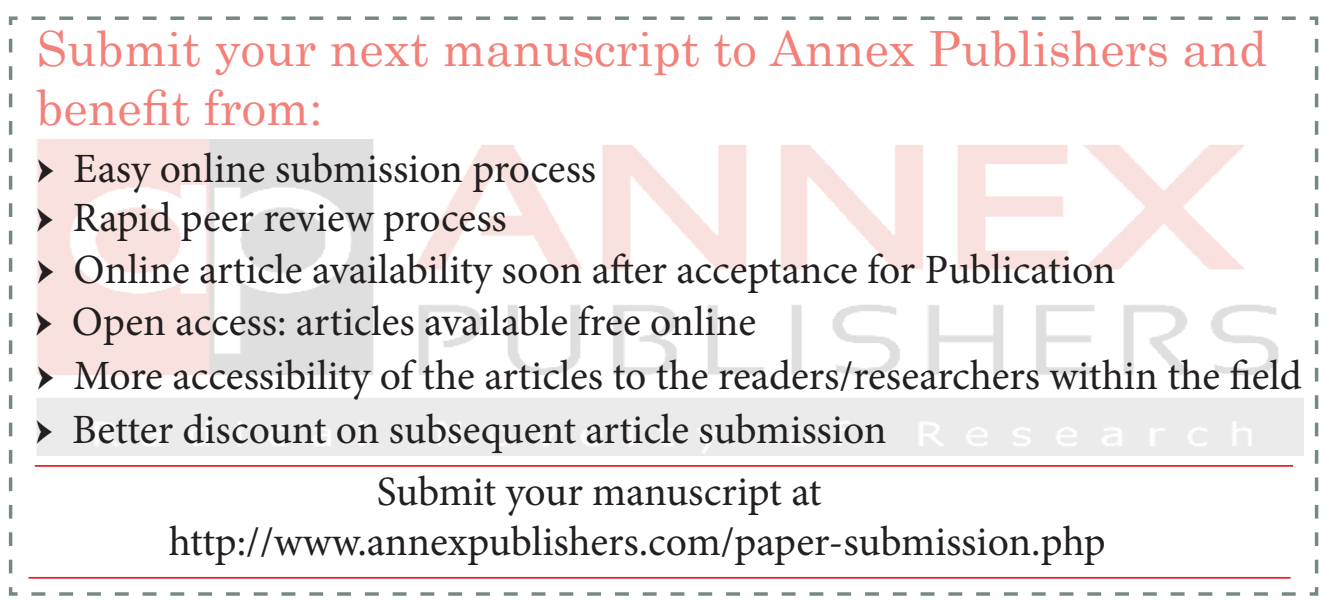

